\title{
"I Want to See Those Memories" : Social Affordances of Mobile Phone Cameras and Social Network Sites in Collegiate Drinking
}

\section{Authors: Gilbert Quintero, Henry Bundy, and Michelle U. Grocke}

This is a postprint of an article that originally appeared in Contemporary Drug Problems on March 14, 2019. The final version can be found at https://doi.org/10.1177/0091450919834970.

Quintero, Gilbert, Henry Bundy, and Michelle Grocke. "I Want to See Those Memories": Social Affordances of Mobile Phone Cameras and Social Network Sites in Collegiate Drinking." Contemporary Drug Problems 46, no. 2 (June 2019): 180-197. DOI:10.1177/0091450919834970. 


\author{
Gilbert Quintero'`, Henry Bundy ${ }^{2}$, and Michelle Grocke ${ }^{3}$
}

\begin{abstract}
Alcohol use remains a prominent feature of American collegiate social life. Emerging technological developments, particularly the proliferation of mobile phone cameras and the easy sharing of digital images on social network sites (SNS), are now widely integrated into these drinking practices. This paper presents an exploratory study examining how 40 students on a midsized college campus in the interior Pacific Northwest incorporate these technologies into their drinking activities. Data from semistructured interviews are considered within the theoretical framework of "affordances," which classifies material technologies (camera phones, SNS) as simultaneously inhabiting the role of artifact shaped by human action and of object that influences human conduct. Our data suggest that although contemporary college drinking reflects long-standing practices, cameras, digital images, and social media introduce new dimensions to college alcohol consumption and memory-making processes. These technologies are used to chronicle and archive the festive, social aspects of drinking; commemorate the good times that make up the college experience; and capture proud or incautious displays of excessive drinking. Our examination of emergent college drinking practices seeks to extend understandings of contemporary trends in collegiate alcohol use beyond the discourse of risk and indiscretion to include other important social and cultural dimensions of these phenomena, including pro-social aspects of these practices and the social affordances provided by digital image sharing and reminiscing.
\end{abstract}

\title{
Keywords
}

alcohol, qualitative research, social contexts, social media, young adults, USA

\footnotetext{
'Department of Anthropology, University of Montana, Missoula, MT, USA

${ }^{2}$ Department of Anthropology, University of Kentucky, Lexington, KY, USA

${ }^{3}$ Department of Health and Human Development, Montana State University, Bozeman, MT, USA
}

Received June II, 2018. Accepted for publication February II, 2019.

Corresponding Author:

Gilbert Quintero, Department of Anthropology, University of Montana, 32 Campus Drive, Missoula, MT 59812, USA.

Email: gilbertquintero@umontana.edu 
This paper presents an analysis of data from an exploratory qualitative research project that examines the intersection of college drinking, social life, and commemorative technologies and media (mobile phone cameras and social network sites [SNS]). Rather than add to established public health descriptive understandings based on frameworks that tend to stress a lack of good judgment and the expression of "risk behaviors" in accounting for and characterizing these media practices, the data presented here are considered within an alternative framework rooted in material technology and media and communication studies. Specifically, we rely on the concept of affordances to put forward an analysis of these practices based on a focus on material technologies (mobile phone cameras, SNS), alcohol use in emergent social contexts, cultural expectations regarding college life, and social reminiscence. This orientation allows us to better understand how sets of relatively new technologies and personal media are integrated into established collegiate drinking practices.

One reason such a focus is warranted is the many media reports and research accounts indicating that American college students are projecting a variety of potentially incriminating images of themselves and their peers into the networked public (Winzenburg, 2012). These accounts seem to suggest that young adults are quite willing to share details about their personal identity and images depicting a range of potentially compromising activities. For example, photographs and videos of public indecency, excessive consumption of alcohol, drug use, personal vandalism, horseplay, practical jokes, and teasing are all easily found on social media. The documentation and dissemination of these activities, specifically those related to collegiate drinking, continue to draw comment and criticism from the media, various officials, and the public.

These activities reflect long-standing practices related to the American college experience and cultural expectations that this life stage is a developmental "time-out" period when young adults engage in excessive alcohol use in an environment that lacks the responsibilities and strictures that come to constrain later life (Amett, 2005; Schulenberg et al., 2001). To a certain extent, these drinking activities represent long-standing cultural practices and are often considered inevitable, if unfortunate, aspects of coming of age and youthful dissipation (Backett \& Davison, 1995; Kett, 1977).

Although these drinking activities reflect enduring practices, technologies such as mobile phone cameras and SNS now afford the means to document and transmit these consumption events in a manner that was unheard of only a generation ago. Today, in a matter of seconds, images of an individual's drunken indiscretion can be captured with a mobile phone camera, uploaded onto a social media site, tagged with an individual's name, and exhibited indefinitely. As a result, photographs and videos that portray the variety of college drinking are widely available.

There are many reminders of the pitfalls associated with this type of social media presence. Wordof-mouth stories circulate within peer social networks and publicized accounts in the news media make clear that images on social media are actively accessed by parents, school officials, law enforcement authorities, and employers. This surveillance can result in social embarrassment, damaged reputations, unsuccessful job searches, expulsion, and even arrests (Read, 2006).

These developments highlight a number of areas for research. For one, they underscore the question "Why do some college students document and post their alcohol use on social media?" On a broader level, these practices invite us to examine the affordances offered by social media and imaging technologies in the context of contemporary collegiate social life, especially within drinking events.

While some students readily participate in the digital documentation of their drinking, others actively seek to avoid such exposure. In contrast to the predominant public health discourse on these practices, the presence of these images is not simply a matter of alcohol-fueled disinhibition or bad judgment but can be understood as the complex result of the affordances of emergent technologies like mobile phones and social networking sites, technologies that now constitute the experience of college life, social drinking, and memory making. 


\section{Literature Review}

\section{Mobile Phones}

The literature on collegiate alcohol use is vast, yet the question of how mobile phones are integrated into collegiate drinking is largely overlooked. Virtually unknown on campuses a generation ago, mobile telephones have moved beyond the status of a simple security or luxury device and today are utilized for a range of instrumental and expressive purposes. College students have been at the forefront of adopting this technology and integrating it into various aspects of their social lives (Smith, Rainie, \& Zickhur, 2011). The widespread use of mobile phones in this population makes it a primary mode of social interchange. Many of the specific characteristics and applications associated with this technology help to explain the rapid diffusion, adoption, and increase in use of these devices among young people, including values of mobility and independence and ease of social communication (Yoon, 2006). In addition, the capacity to produce digital images with mobile phone cameras and share them from these devices onto networked social media platforms provides opportunities for self-expression, affirmation of important social relationships, and memory-making activities that many find attractive (Livingstone, 2008; Mendelson \& Papacharissi, 2010). As a result of these functions, mobile phones have become widely integrated into the social lives of young people to the point that these devices cannot be understood as simply a part of a technological tool kit but also as an important component of users' social networks. In the words of one research in this area, the ubiquity of computer-mediated communication makes these technologies "embedded, embodied, and everyday" (Hine, 2015).

Despite their widespread integration into many social settings, there are few qualitative studies on mobile phones in the context of collegiate drinking. The extant research on mobile phone use among college students tells us little regarding how these devices relate to alcohol use in group settings, but instead focuses on the evolving social rules of etiquette surrounding mobile phone use among collegians (Lipscomb, Totten, Cook, \& Lesch, 2007), cross cultural explorations of similarities and differences in perceptions, and uses of mobile telephony (Campbell, 2007), and how students use these devices to facilitate sexual activity (Dir, Cyders, \& Coskunpinar, 2013; Renfrow \& Rollo, 2014).

In spite of their integration into the social lives of young people, there has been little effort extended toward examining mobile phones in the context of alcohol use in collegiate settings. More specifically, there is little research that contributes to our understandings of mobile phones as material objects embedded in social drinking practices and the role these technologies play in shaping emergent contexts of college drinking.

\section{SNS}

In contrast, the sharing of various media produced with mobile phones, particularly digital images and videos shared on SNS, is the focus of a great deal of research and commentary. The adoption of SNS use among college students illustrates a trajectory similar to that noted for mobile phones. Boyd and Ellison (2008) define SNS as

web-based services that allow individuals to construct a public or semi-public profile within a bounded system, articulate a list of other users with whom they share a connection, and view and traverse their list of connections and those made by others within the system. (p. 211)

SNS provide a means for people with common interests, acquaintances, lifestyles, and activities to communicate and share information and media and have several features that foster social interaction. Since their introduction, these sites have become increasingly popular, especially with young adults (Smith et al., 2011). 
Mainstream research on SNS focuses on identity presentation, privacy concerns, and the online performance of friendship networks, as well as considerations of race, ethnicity, class, and gender issues and the connections between online and off-line sociality (Boyd, 2007; Gross \& Acquisti, 2005; Stutzman, 2006). Although there is less research on the drinking practices of young people on SNS, analysis suggests that such practices are common (Glassman, 2012; Moreno, Parks, \& Richardson, 2007). The principal line of investigation in this area describes the range of risk behaviors presented online that typically underscore the routine nature of these sharing practices in collegiate social groups. The content of these descriptions predominately focuses on underage and heavy drinking and to a lesser extent recreational drug use and sexual expression (see Paradise, 2012). Other studies go beyond these depictions and suggest that the presentation of such images is correlated with certain risk behaviors and negative outcomes. Thus, college students who display online profile pictures that show them drinking are presented as being more likely to engage in severe, episodic drinking and to exhibit poor academic performance than individuals who do not project this type of online presence (Moreno \& Egan, 2011). Finally, other investigators emphasize how SNS such as Facebook enable a type of ongoing dialog among young women and serve to mediate their drinking experiences and social relationships (Brown \& Gregg, 2012). Importantly, in this context, even "risky" and "regrettable" experiences become the foundation for peer bonding and retrospective enjoyment of social activities.

Since their introduction, these sites have become increasingly popular, especially with young people. One SNS, in particular Facebook, is the predominant choice among college students (eMarketer, 2015). Facebook was chosen as the focus of this investigation due to the popularity and stability of this SNS, along with its relative prominence in the college drinking literature.

\section{Social Affordances, Technology, and Alcohol Use}

A related body of studies emphasizes the ostensibly unreflective nature of online portrayals (Peluchette \& Karl, 2010). At issue is not simply the act of posting these types of images publicly but doing so in a way that makes them readily personally identifiable. The inclusion of personal information-most often personal names - can result in negative repercussions when an authority figure judges an image or a post to be in poor taste, lewd, unprofessional, or illegal. In these circumstances, the images produced with mobile phone cameras and posted on social media sites can produce unintended social ripple effects that may result in job loss, expulsion from college, or legal difficulties. While some of the potentially problematic disciplinary functions and effects of these discursive practices have been pointed out (Brown, 2013), this remains a predominant frame for describing and understanding college party photography in both the scholarly literature and popular media.

While these analyses provide fundamental understandings regarding the scale and character of online photo sharing of collegiate drinking, they are arguably underdeveloped in light of recent studies of young people's use of intoxicants in social context and insights provided by examinations focused on social materiality (Demant, 2009; Law, 1999; Race, 2014). Put a different way, a more direct consideration of how the material presence of technological objects (mobile phone cameras) and their products (digital images) relates to emergent drinking practices can extend our understandings of contemporary trends in collegiate alcohol use beyond the discourse of risk and indiscretion to include other important social and cultural dimensions of these phenomena, including pro-social aspects of these practices and the social affordances provided by digital image sharing and reminiscing.

\section{Theoretical Framework}

The place and impact of material objects in drinking events has been a recurrent analytical focus. Here, the interest is on how various artifacts come together in social context to constitute drinking 
experiences or how certain culturally meaningful objects are constructed and incorporated into particular consumption acts. For the most part, these analyses have emphasized alcohol as a material force that encourages individuals to adopt certain styles of drinking and to enact a particular, drinking self (cf. Cocker, Banister, \& Piacentini, 2012).

At the same time, similar analytical considerations have been developed on a parallel track in examinations of technological impacts in human societies. Originating in studies of perceptual and environmental psychology (Gibson, 1979), the concept of "affordances" has been put to use to understand the characteristics of material objects and their impacts in specific settings, and it provides a useful heuristic for consideration in the present context. In many accounts, affordances are functional aspects of an object that frame its possible uses or actions (Hutchby, 2001). Affordances are relative and relational, rather than deterministic. Viewed through this lens, technologies have a utility shaped by human practice, while simultaneously shaping possibilities for human use and action by virtue of their material features. This approach to understanding human relationships with objects has extended to science and technology studies and actor-network theory-lines of investigation that emphasize the mutually constitutive nature of technology and society (Latour, 2005).

Within the domain of social media studies, there are important general analyses of affordances that focus on the basic technological capacities of SNS as networked publics; on distinct, structural affordances - persistence, replicability, scalability, and searchability, for example - and their social ramifications on various practices (Boyd, 2010). In a similar vein, other studies center on developing analytical typologies related to communicative affordances associated with mobile media, including smartphones and tablets, by considering aspects of portability, availability, locatability, and multimediality (Schrock, 2015). It is important to note that some investigators are engaged in efforts to extend the use of affordance as an analytical concept beyond the domain of technology, media, and communication studies in order to offer a more general model of affordances that goes beyond a technological focus while attempting to avoid some of the many definitional ambiguities associated with this framework by focusing on more specific mechanisms through which affordances are manifested (Davis \& Chouinard, 2016).

Despite these efforts and the application of affordance approaches to domains beyond perceptual psychology, there has been little work advanced in the realm of alcohol and other drug studies which utilizes this framework. A notable exception is recent attention to the social materiality of interpersonal relationships and harm reduction technologies among people who inject drugs in the context of hepatitis C prevention efforts (Fraser, Treloar, Gendera, \& Rance, 2017). Redesigning technological objects (i.e., storage cases for injection equipment and supplies), as well as related reconceptualized prevention messages, created new affordances for couples engaged in injecting drug use who wanted to integrate safer routines into their repertoires. A new complementary, more couple-friendly, physical design afforded people opportunities to engage each other in new ways that allowed for the expression of love and care, responsibility, and new types of communication.

It is not our goal here to establish theoretical or definitional closure regarding affordances. Instead, we seek to use this concept to expand our understandings of what certain artifacts afford in one particular social context, collegiate drinking, and to identify a more diverse and complex set of subject-artifact relationships than is typically recognized. Using data from an exploratory qualitative study, we underscore how a cluster of technologies, including mobile phone cameras, digital images, and SNS, afford a means for undergraduates to participate in memory making and other important aspects of collegiate social life, while at the same time activating potential threats to privacy and incrimination. Using the framework of affordances, the present analysis attempts to illustrate how mobile phone cameras and digital photos shape collegiate drinking practices, self-presentation, and social interactions, rendering heretofore semiprivate spaces - dorm rooms, frat houses, undergraduate parties, and so on-visible and public, and presenting young drinkers with the responsibility of continually curating their digital identities. In doing so, these objects facilitate the performance of a 
certain type of collegiate identity for some, but can also serve to chill the social expression of others. There are few studies that examine the integration of mobile phone camera photography, SNS, and collegiate alcohol use. This lack of research represents a major gap in our understandings of contemporary drinking trends on college campuses as well as a lacuna in the literature regarding the place of technologies and social media in the context of everyday social practices in emerging adulthood.

\section{Method}

Data collection procedures consisted of face-to-face interviews with unstructured and semistructured elements conducted with $\mathbf{4 0}$ undergraduate students at a liberal arts institution in the interior Pacific Northwest of the United States. Interviews focused on developing an understanding of the cultural knowledge regarding the use of mobile phone cameras and SNS and their relation to drinking in a collegiate context. Interviews examined key aspects of knowledge, attitudes, and behaviors related to drinking, SNS, and mobile phones. Topical areas explored include the following: individual phone and SNS use, descriptions of recent occasions when mobile phones and SNS were used to organize, participate in, document or comment upon a social activity that involved alcohol use; alcohol use histories; social life and peer relationships; and alcohol use at social events. Interviews were audio recorded, saved as digital files, transcribed, imported into a qualitative analysis program, and then coded and further analyzed.

Analysis followed a set of coding procedures described by Miles and Huberman (1994). This approach entails developing a coding scheme through line-by-line reading of interview transcripts (Strauss \& Corbin, 1998). The initial level of coding was predominately deductive - it captured descriptive, structural aspects of the data, such as specific interview questions and responses. This procedure allowed researchers to systematically organize and examine responses to each of the interview questions across all respondents in order to carry out the next type of analytical procedure, inductive (pattern) coding. Inductive coding was conducted at multiple conceptual levels with categories derived from more basic words and statements. Question-level responses were coded for more specific replies at a word or statement level. This produced sets of words or statements organized within question-level categories. Next, each set of words or statements was examined and semantically identical responses were collapsed into a single code. Codes within each question category were then reexamined to determine whether they could be collected together under a more comprehensive category, with a specific focus on identifying repetitions that indicated themes (Ryan \& Bernard, 2003). If so, such a theme was created as a code or subcategory within each question-level code. Interview data were examined to discover any patterns and relationships relevant to mobile phone cameras, SNS, and drinking. As categories emerged from this process, a coding system was developed so that transcripts could be indexed and systematically analyzed. This procedure allowed for the recognition of repeated, dominant themes.

The procedures described here are based on principles of qualitative sampling, which generally intends to capture the full range of major cultural characteristics that are present in a particular social group (Becker, 1996). Some approaches to qualitative sampling work on the basis that a set of approximately $15-30$ individuals from a culture collectively contain the range and major components of knowledge and experience that exists for a particular cultural domain (Trotter, Needle, Goosby, Bates, \& Singer, 2001). In other words, individuals within a culture can provide the major core beliefs, knowledge, and information that exists in a larger cultural group. One strategy for gaining access to such well-informed individuals is through purposive sampling - the process employed in this study. This selection process is based on the idea of theoretical representativeness. The researcher chooses informants from segments of a social system that are meaningful in terms of the investigator's research interests. The goal of purposive sampling is to get "information-rich cases" (Johnson, 1990) for indepth study —interviews with individuals that are experts in a particular cultural domain. 


\section{Recruitment and Screening}

Interviewees were selected by utilizing a framework that targeted specific aspects of alcohol use and technology utilization. In order to maximize participation and minimize problems associated with closed recruiting forums such as classrooms, recruitment was organized on the use of advertisements. Recruitment advertisements were placed in the student newspaper and a local entertainment magazine, and handbills and flyers were posted at social venues frequented by undergraduates. The ad included basic information about the study and a phone number to call for further information. Those responding were asked how they heard about the study and were vetted according to the project's selection criteria. To participate in an interview, individuals had to be (1) an alcohol user, defined as any alcohol use within the last month; (2) a technology user, defined as an individual who goes online at least once a week, has a Facebook account, and a mobile phone camera; and (3) an enrolled undergraduate student. A total of 54 individuals called in response to the ads and were screened. Of these, 48 met the inclusion criteria and 40 completed interviews.

In the following analysis, quotes from interviews are utilized to illustrate particular aspects of drinking, digital photography, and social media use. These quotes were edited, or subjected to "naturalized transcription" (Bucholtz, 2000), in the following ways. First, linguistic hesitation phenomena (e.g., words such as "uh") were deleted. Second, other common utterances that characterize informal conversation but break the flow when appearing in print were also removed (e.g., words such as "okay," "you know"). Third, these passages were corrected for grammar and clarity where necessary. Fourth, responses were sometimes abridged due to space considerations. Respondents are represented with pseudonyms in the following presentation. An example of this editing procedure is provided in the Appendix.

Data collection took place in a private setting, and each interview lasted approximately 1 hour. Individuals were compensated with US\$20 cash for completing an interview. All research procedures and protocols, including recruitment processes, interview guides, and informed consent forms, were reviewed and approved by the University of Montana Institutional Review Board (approval number: 141-09), and all interviewees provided written informed consent to participate in this study.

\section{Sample Characteristics}

The respondents ranged in age from 18 to 25 years (average age $=20$ years). It is important to note that the legal drinking age is 21 years. Thus, many of the sample engaged in underage drinking. Compared to the general institutional student body, males were overrepresented in the sample ( $58 \%$ vs. $46 \%$ ) as were Whites ( $93 \%$ vs. $76 \%$ ). Almost two thirds of the participants lived on campus. The sample predominately comprised undergraduates - $63 \%$ were first- or second-year college students (compared to $44 \%$ in the general undergraduate population). These and other descriptive characteristics are summarized in Table 1. Pseudonyms and sociodemographic data are provided for the 15 individuals who are cited in the analysis to follow, most of whom described themselves as "White" (Table 2). The sociodemographic characteristics of the sample should be kept in mind when evaluating the results to follow.

Mobile phone cameras are omnipresent at collegiate social events-virtually everyone (95\%) recalled participating in at least one occasion that was documented with a mobile phone camera and later posted on an SNS. In general, interviewees felt that the material presence of a mobile phone camera at a social event altered the behavior of participants but did so in two somewhat contradictory fashions. For those relatively unconcerned about their drinking being documented, this technology inspired them to exhibit or even exaggerate certain behaviors, including those involving alcohol use, so that these activities were captured in a manner that emphasized revelry and perhaps at times even indulgence, as drunken disorder could be an indication of a good night (cf. Brown \& Gregg, 2012). 
Table I. Participant Sociodemographic Characteristics.

\begin{tabular}{|c|c|}
\hline Sociodemographic Characteristics & Percentage \\
\hline \multicolumn{2}{|l|}{$\begin{array}{c}\text { Average Age } \\
20 \text { Years }\end{array}$} \\
\hline \multicolumn{2}{|l|}{ College class } \\
\hline First year & 43 \\
\hline Second year & 20 \\
\hline Third year & 15 \\
\hline Fourth year & 18 \\
\hline Other & 5 \\
\hline \multicolumn{2}{|l|}{ Gender } \\
\hline Male & 58 \\
\hline Female & 43 \\
\hline \multicolumn{2}{|l|}{ Residence } \\
\hline Coed residence hall & 45 \\
\hline Single-sex residence hall & 13 \\
\hline Apartment & 23 \\
\hline House & 18 \\
\hline Other & 3 \\
\hline \multicolumn{2}{|l|}{ Racial background } \\
\hline American Indian/Alaska Native & 5 \\
\hline White & 93 \\
\hline Refused & 3 \\
\hline Hispanic ethnicity & 8 \\
\hline \multicolumn{2}{|l|}{ Living arrangement } \\
\hline Self (alone) & 10 \\
\hline Roommate(s) & 80 \\
\hline Boyfriend/girlfriend & 5 \\
\hline Other & 5 \\
\hline \multicolumn{2}{|l|}{ Employment status } \\
\hline Full time & 10 \\
\hline Part time & 25 \\
\hline Not employed & 65 \\
\hline
\end{tabular}

Note. $\mathbf{N}=\mathbf{4 0}$.

Table 2. Participants Cited in the Analysis.

\begin{tabular}{llllll}
\hline Pseudonyms & Gender & Age (Years) & Residence & Race & Hispanic \\
\hline Chloe & Female & 18 & Coed dorm/residence hall & White & No \\
Jacob & Male & 22 & House & White & No \\
Michael & Male & 23 & House & White & White \\
Aaron & Male & 21 & Apartment & White & Yes \\
Daniel & Male & 19 & Coed dorm/residence hall & White & No \\
Sarah & Female & 19 & House & Declined & Yes \\
Ryan & Male & 19 & Coed dorm/residence hall & White & No \\
Alex & Male & 18 & Coed dorm/residence hall & White & No \\
James & Male & 19 & Single-sex dorm/residence hall & White & Yes \\
Emma & Female & 18 & Single-sex dorm/residence hall & White & White \\
Jennifer & Female & 19 & Coed dorm/residence hall & White & No \\
Jordan & Male & 22 & Apartment & White & No \\
Kevin & Male & 22 & Coed dorm/residence hall & White \\
Lauren & Female & 22 & Apartment & No & \\
Adam & Male & 21 & House & & No \\
\hline
\end{tabular}

Note. $n=15$. 
Others, who are more worried about the potential social damage of such images, however, attempted to avoid being caught engaging in these practices out of concerns that such pictures might damage their social, academic, or future professional reputation.

\section{The Unconcerned}

Members of the first group ( 22 of the 40 interviewed) present themselves as generally being unconcemed: They actively and unabashedly embrace the use of mobile phone cameras to document various aspects of their collegiate social lives, including drinking. These individuals may deliberately document their participation in these activities. Chloe, an 18-year-old woman, noted that some people "want to get that snapshot of them being a party animal." These drinking activities take a variety of forms, from individuals simply posing with a beer in hand to engaging in more extreme forms of drinking by utilizing "beer bongs" or performing "keg stands." 1 These activities also include striking poses, beaming bogus smiles, or engaging in horseplay.

At times, the material presence of mobile cameras seems to compel this behavior. As Jacob, a 22-year-old student, noted, "No one wants to be the boring person in the picture." In some circumstances, this posturing extended to prominent displays of intoxicant use, most commonly, the consumption of alcohol. Michael, a 23-year-old man, was quite candid about his participation in this type of behavior when he readily pulled out his phone during an interview to share several images depicting drinking. While doing so, he provided the following commentary:

We had a keg stand competition. I lasted for 64 seconds and people congratulated me. $<$ Scrolls to next picture>. Here's a picture of a beer in my hand. I'm at the football game. <Scrolls to next picture>. Here's an example of a picture that has kegs of beer, a stripper pole, a bong, and a glass of beer.

Others documented and displayed their drinking activities in a different manner that highlighted the amount of alcohol they imbibed. Aaron, a 21-year-old man, related an experience he had while living in a campus residence hall:

I lived in a dorm my freshman year and we built a table made out of Pabst beer cans. I used it as a coffee table, but I remember one of my roommates took a picture of it and posted it. We had an issue with the dorm people, them saying, "You can't have this in here!" That's a thing people do is take pictures of their empty bottles, cans, or whatever.

These examples suggest that particular drinking experiences are sometimes commemorated through the construction of temporary tableaus and monuments, and also memorialized and given a second social life through the posting of images and commentary. Such events are the subject of visual documentation precisely because they center on alcohol use. Other similar examples include beer bong parties, keg stand competitions, and beer pyramids. ${ }^{2}$

The consumption activities described by these students are part of a larger range of social events involving alcohol use and were commonly documented with mobile phone cameras and posted on SNS. One indication of the ubiquity of mobile phone imaging is the range of social activities that college students record with these devices. This includes events connected to social and academic calendars, such as commemorative occasions associated with birthdays (most notably 21 st birthday celebrations that announce the celebrant's entry into legal drinking age) and semester kickoff and finals parties as well as certain holidays (e.g., Halloween). Other occasions taken in by digital images include various types of parties organized around individuals dressing in costume. Students report participating in pirate parties (where attendees dress as pirates), Minnesota parties (where individuals dress as if they are residents of that state), and even mustache parties (a.k.a. "mustachio bashios") —a 
social get-together where a Sharpie marker is available at the door and attendees are not allowed entrance until they draw a mustache on themselves. Other social gatherings revolve around specific events connected to campus life, such as tailgating at football games. These are all in addition to more run-of-the-mill, "random" parties, such as those described by Daniel, a 19-year-old man:

There are a lot of pictures of random parties, not necessarily a huge party but, we'll go to my friend's house and drink. Then at the very beginning of the year, when everybody was just starting to get to know each other, we used to go down and drink by the river a lot, probably 3 or 4 times a week and there'd be 20 to 25 people down there and pretty soon people are really drunk and they start pulling their cameras out and taking pictures. And in all the pictures,youcan see the beer in people's hands. Yeah, there are a lot of pictures up on Facebook from that.

Interviewees provided several explanations to account for this process of display. These included the notion that some people simply enjoy the attention that a photograph provides. Another explanation suggested that partyers caught up in the moment, usually due to the effects of intoxication, did not fully consider the possible repercussions. Others are apparently less concemed because they do not perceive what they are doing to warrant social sanction. For those more open with their parents about their alcohol use, for instance, there appears to be less concern about being seen drinking, especially once they reach legal drinking age. These interviewees seem inclined to experience this phase of their life as they see fit, even if it is documented in a less than flattering manner. As Sarah, a 19-year-old woman, pithily summarized: "I'm going to do my thing and live my life the way that I want to and I don't really care who sees it."

Ryan, a 19-year-old man, noted another key aspect of this type of documentation-it adds to the atmosphere of a drinking occasion and provides the opportunity to revisit the experience:

When you have a camera and you're drinking, it adds excitement because you want to document what's going on and how you feel, especially if you have a video camera. I know that if I get really drunk I pull out my video camera and I'm like, "I'm going to record this so we can see how fucked up we are in the morning." And the next day when you look at it you're like "Wow, I can't believe I was that trashed."

Here, the material object, a camera, contributes to the experiential quality of an emerging drinking event. The social activity is seen as being "more exciting," than it might otherwise be, and a new intentionality and dimension is introduced that will allow the drinking event to be revisited and evaluated at a later time.

This process of capturing drunken images and disseminating and commenting upon them on SNS fulfills social functions that extend beyond the documented occasion and may help explain why college students participate in this process. For example, these images provide an avenue to express teasing relationships within peer groups and at the same time serve as a means to capture social life and provide a prompt for reminiscence. Alex, an 18-year-old man, noted:

We have a general mentality that it's funny to embarrass each other. We have videos on phones of people dancing and then falling over, losing their pants, that we find amusing. I certainly wouldn't want to damage someone's career potential or anything. I'd feel really bad about that, but if it was just in an album of my friends, where we were obviously at a party, then I'm not too concerned about posting that because it's our central event, a way to record what we do. I want to see those memories.

Likewise, Chloe, an 18-year-old woman, conveyed the following:

I guess the last pictures we put up were when <laughing $>$... we weren't even drinking a lot, but I somehow managed to tip over a Mike's [Hard Lemonade] and it shot out across the kitchen and started spinning <laughing> and it covered the ceiling, and the walls, so they have pictures of me cleaning the kitchen surrounded by bottles. 
Particular features available on SNS facilitate this process by providing users with the capacity to explicitly identify individuals in images, direct comments on their appearance or behavior, and evaluate the experience after an event has concluded. These comments include simple reminisces about having good times together, but also involve teasing, veiled criticism, and personal humiliation. The following two exchanges illustrate how these types of features are linked with social processes.

\section{Exchange 1:}

Interviewer: Do people ever comment about you on those photos when they're posted on Facebook?

Respondent (James, 19-year-old male): Yeah, definitely.

Interviewer: And what are those comments like?

Respondent: Like, "I bet you don't remember this" or "Rough night!"

Exchange 2:

Interviewer: When you go to these parties, has anyone ever documented it on Facebook?

Respondent (Emma, 18-year-old female): Oh yeah, definitely ... definitely picture taking and reminiscing on the following day. "Oh, do you remember when this happened?"

Interviewer: I was just wondering if people used it more for positive reinforcement or sort of to make fun of somebody?

Respondent: Definitely both. You'll get the picture of someone passed out who's been colored all over and had their clothes stripped off. I think that's really mean. It's a dick move for sure. I wouldn't do that. And it puts the person in a really bad, embarrassing position, especially if it's tagged and they don't know until they get online. Facebook is risky. So many people I know have parents and teachers as friends and it definitely creates a sort of a gray area of how far you go with what you do.

Here, we see recognition of the ambiguity and social risks generated by objects in collegiate social milieus. Mobile phone cameras provide social affordances when capturing the fun experiences and good times that help constitute college social life and even good-natured teasing surrounding images can provide a means to bolster friendships, but at the same time, there is appreciation of the fact that such images can have negative impacts in certain social fields. For some, these more negative considerations become more intrusive and predominant considerations when cameras enter into certain social settings.

\section{The Concerned}

In contrast to individuals who eagerly participate in the photographic documentation of their alcohol use, there are those who express much more ambivalence about this process and who may even consciously attempt to avoid it. Fifty-six percent of respondents either stopped such a picture from being taken at a party or requested that it not be posted on an SNS. Others attempt to manage these sorts of images by seeking them out and removing identifying tags. As Jennifer, a 19-year-old woman, noted:

I think that anyone who doesn't want to get their picture taken will just avoid it, but overall, it is just... "Oh, I know there is a camera at that party, I am going to get on Facebook and untag myself."

Thus, instead of going to the source and requesting that people not take pictures, respondents indicated that they check social media sites on a regular basis in order to untag themselves from photos that they 
do not want to be associated with. Several interviewees indicated that they participate in this type of image management on a regular basis. It is clear that at least some individuals dedicate time to this maintenance work even as they manage other aspects of college life. Facebook also allows users to have control over their use-settings-and although we did not ask specific questions regarding which of these settings are preferred by participants, privacy settings have been the center of numerous news stories and could also be viewed as a mechanism of affordance.

The availability of imaging technology and its potential for disseminating socially harmful information is a source of concem. Eighteen of the forty students interviewed expressed fear of future employers seeing these images or that the pictures might be viewed by parents, family members, law enforcement, or school authorities. In addition, some expressed a general unease that an uncomplimentary photo might appear at an unknown point in the future when it might be socially damaging. These realities can have a dampening effect on social activities involving alcohol use. Jordan, a 22-year-old man, summarized this aspect of collegiate social life in the following way: "Everything you do is so public." He continued:

It does make people more reluctant toget down because they know that these pictures are all over Facebook and anyone can see them, even if they're not your Friend. People think that if they don't Friend their parents then they will never find out. But if their parents wanted to they could just go find an agency that can crack into Facebook. I have friends that really go through a lot of anxiety over pictures on Facebook.

Living in the age of Facebook inspires young adults to engage in contemplation about their future social reputation in new ways. Kevin, a 21-year-old man, related the following:

I have been thinking about those drinking types of photos a lot more lately. I want to be a high school teacher and in one of my classes we read this article called "Google Never Forgets" about this guy who was hiring babysitters and he would Google their name and all these pictures came up. And none of them were really that flattering. I've been thinking a little more about that lately because I do know that employers look at your Facebook when considering employment. I've been trying to clean out my Facebook as much as I can.

Thus, college students express awareness that images of drinking are a potential source of surveillance. These social and technological realities compel some individuals to direct a new attentiveness to their activities. Lauren, a 22-year-old woman, describes this situation:

I think there is a really distinct phenomenon at party situations nowadays, especially group situations where there is a hyperawareness of everyone that these [pictures] will end up on the Internet, rather than someone just taking your picture. So you have these mixed groups of people that see the camera, migrate toward the camera because they want to be on the Internet and look cool, like they were at a party or whatever. And then you have other people that are like, "I need to move in another direction."

This passage underscores how the presence a particular material object, a mobile phone camera, can initiate certain avoidance strategies in drinking events. One interesting aspect of these practices is that they seem to have changed over a relatively short time period. While open, unreflective posting of social images may have been unproblematic in the past, in more recent times, individuals see it as being increasingly troublesome. Lauren's comments on these developments are particularly insightful:

When it first started I was not worried in the slightest, because it felt like such a tight knit community. It was just the college kids I knew. It was so locked down on Facebook you couldn't even see anything other than this little picture. It felt very secure. Now, that's obviously changed. Everyone I know has gone through steps to make sure they're mindful of their main profile picture and the pictures that end up online. There is 
definitely more of a mixed feeling. It's cool to have this online record of all these things. It's neat that we can look at the fun times we were having. But at the same time there's definitely the sense that other people can see these. For a lot of people it's made them more careful. It doesn't bother me especially at this age as long as I have a mix of pictures and I'm not being a drunk skank on the Internet. I'm not like lifting up my skirt and letting people take pictures of me when I'm passed out or puking.

Thus, some individuals express increasing sensitivity over time in their attitudes regarding picture posting on SNS. They are a segment of the collegiate population concemed that their social lives are being documented and that any uncomplimentary images could reach an unintended audience. These worries prompt some to take deliberate measures to conceal their activities and identities. There are a number of strategies for managing the social risks involved in posting images. These include untagging photos, deleting untoward comments, requesting that specific photos be removed, and simply not posting photos. Another approach involves being more discreet by using the private message application available in Facebook to comment on an activity instead of posting such remarks where they would be more potentially incriminating. Other individuals attempt to avoid appearing in compromising positions by not being photographed in certain situations. For some, this led them to opt out of any picture where it was obvious that alcohol use was taking place, while for others, this meant restricting certain activities to closer friends who could be trusted not to engage in indiscreet posting and thus reinforcing friendship ties.

Some individuals recognize an emerging form of etiquette related to these concerns: Individuals amnouncing to party participants that photos had been posted on an SNS and that they could review these and ask for them to be removed. Other approaches to avoid socially harmful outcomes include monitoring the use of mobile phone cameras at parties in order to engage in effective impression management when intoxicated. There are varying levels of comfort with different situations; some expect that no drug use should be shown, but that images of alcohol use are acceptable.

Overall, students face a situation where they want to be involved in the social activities that college life offers but are aware that technologies not only present new opportunities to facilitate these activities but new complications as well. Adam, a 21-year-old man, reflected on these realities in the following way:

There definitely are folks who totally put alcohol in the forefront. Then, there are some folks that when you pull a camera out they put a beer can behind their back even though you obviously know it's a party. I think especially with younger people showing the fact that you do party is associated with social stereotypes that we have that it's the cool thing to do. But then, there's a negative connotation. People think you're cool when you do that but then you bring up drinking and people think you're bad too. So it's a weird balance. There are folks who don't want to be caught at parties, even though they do drink. They don't want people to know that they drink, because other people might have negative expectations of them. I mean if you go out to the bars and someone pulls out a camera you usually don't get crazy, but if you're at a party there's more peer pressure and expectations. If you want to be the life of the party, you usually have to do the craziest thing. So some people try to do extreme things.

This passage underscores an important aspect linking mobile camera phone images and drinking. These objects do not simply document activity; in some instances, they appear to shape practices that project a particular social image.

\section{Discussion}

User-generated images both capture and display important social activities that help define a culturally distinct segment of the life phase, a time and place known as "college." These images captured on mobile phone cameras and circulated through social media depict interactions in social fields organized around drinking as a central collegiate activity. These pictures often portray peer groups having 
good times and tend to emphasize the quantity of alcohol consumption, intoxication, and an individual's ability to manage drunkenness, at a range of social events. These material objects have the ability to project and realize an image of college life; however, while some individuals actively seek to share these images, others view them with more ambivalence. Here, we draw out what we see as important implications of this research.

One point to highlight is that these technologies enable both the taking and sharing of photos, actions that fulfill important social functions. These images provide an avenue to express teasing relationships within peer groups, while simultaneously serving as a means to capture social life and provide a prompt for reminiscence. Mobile phone camera images and social media enable college students to encounter and reencounter drinking in a socially important way. Images of particular types of drinking, be it run-ofthe-mill parties or drinking games, serve as keepsakes as well as visual indicators that individuals are living out certain expectations associated with college life. The commemorative aspects of photos underscore the fact that drinking encounters are not simply risk behaviors directed at attaining certain levels of intoxication, they serve as objects of memory making as well.

In addition, images of monuments to drinking, drinking competitions, and similar actions fulfill other social functions. Images that capture individuals engaged in extreme drinking - photos of keg stands, for instance-display certain features that extend beyond the actual drinking occasions which they document. These images of extreme drinking may be an expression of "edgework" - the practice of voluntary risk-taking in which an individual attempts to skillfully negotiate the boundaries of risk (Lyng, 2004). In this case, it is worth considering if individuals are not only attracted by the experience of "being on the edge" but may also utilize digital imaging technology to chronicle, certify, and communicate this ability in order to establish prestige within their social circles. This socially oriented use of technology is in line with other research on the "intimate edgework" young people engage in as they derive satisfaction from posting images that navigate boundaries between the public and private even as they risk possible embarrassment and loss in social standing (Hart, 2017).

Mobile phone cameras and social media afford a set of technologically framed drinking and commemorative practices, "trophy drinking," a culturally stylized form of extreme drinking (Martinic \& Measham, 2008), whereby peer groups utilize digital imaging technology, telecommunications networks, and social media sites to document and memorialize their experiences. This type of collegiate partying and reflection echoes the sociality associated with collective consumption of alcohol by young people as a means to display and enact social commitments to friends noted in other research (Demant \& Østergaard, 2007).

Smartphone photography and SNS enable college students to perform the work of memory making that constructs this aspect of their collegiate social experience. In this case, images of alcohol consumption illustrate success in carrying out certain culturally valued activities. These images document various aspects of competency in drinking and facilitate positive remembrance of drinking experience, even in some cases where there are negative outcomes. In this way, digital photos and videos become trophies in and of themselves - they indicate success in attaining a particularly culturally valued pursuit and highlight prized qualities that may enhance prestige or social status within peer networks. These trophies are objects that relocate drinking occasions beyond the space and place where they originated, and they become objects of remembrance of certain culturally valued aspects of "college life."

\section{Conclusion}

Before concluding, it is important to underscore several specificities of the study described here. Given the existing empirical base of studies available, the popularity of the platform among college students, and the exploratory nature of this investigation, Facebook was chosen as a target for investigation. Other social media platforms have different functionalities and, we presume, may offer different affordances. In addition, the sample was predominantly White, male, and under drinking age. While 
these categories represented the population of the institutional setting to a certain extent, a study focusing on females and/or ethnic/racial or other minorities might identify different practices and understandings.

Within these parameters, however, it is possible to identify mobile phone cameras and digital images as key technologies for documenting and shaping collegiate drinking encounters in ways that were not possible even a generation ago. These technologies have a particular utility for chronicling and archiving the festive, social aspects of drinking; commemorating some of the good times that make up the college experience and also for capturing and displaying excessive drinking - which can also be recalled as good times (Brown \& Gregg, 2012). Further research is needed to clarify whether the practices identified here are common among students irrespective of gender and ethnic/racial background or whether they are largely restricted to the traditional beneficiaries of college education: White, predominantly middle-class males.

One important domain for investigation relates to the extent to which interactions involved in picture taking and SNS posting influence how users construct their experiences, reflect upon their own conduct and that of others, and consider their future social standing. Technologies allow individuals to be active producers of media, not simply consumers. As a result, young adults can control the production of their own images and identities to an unprecedented extent - be it the responsible agent or the unconcerned happy-go-lucky party animal. Ultimately, attention to the social affordances of mobile phone cameras, digital images, and SNS has implications not only for understanding and addressing college alcohol use but for studies on the social materiality of drinking as well.

While much of what we see in college drinking reflects long-standing practice, cameras and photos introduce new dimensions to these activities to the extent that they produce novel drinking and memory-making processes. These dimensions are important to recognize in order to develop our understandings in a number of conceptual and analytical domains that have traditionally been the focus of investigation including the psychosocial processes associated with emerging adulthood, identity development among young adults, the contextual factors framing drinking behaviors, the motivations underlying drinking, and social media use.

\section{Appendix}

\section{Example of Transcription Editing}

Original (Daniel). Let's see, there's defiantly some specific times. Um, can you give me a second, I mean there are a lot of pictures of just like random parties. Um, like just a lot of times it's not necessarily like a big rage-er or huge party but we'll do to my friend's house and drink and then ... actually this is better, at the very beginning of the year, um, when everybody was just starting to get to know each other and it was still warm out, we used to go down and drink by the river, a lot, like probably 3 or 4 times a week and there'd be like $20-25$ people down there and then like pretty soon people are really drunk and having fun and like happy and stuff and pulling their cameras out and taking pictures of the river and in all the pictures you can see the beer in people's hand and stuff like that, but yeah, I mean there's a lot of pictures up from that.

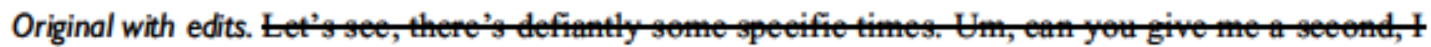

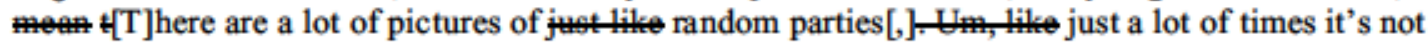
necessarily tike a big party but we'll go to my friend's house and drink[.] t[T]hen... . at the very beginning of the year, when everybody was starting to get to know each other we used to go down and drink by the river a lot, the probably 3 or 4 times a week and there'd be like 20 to 25 people down there and thentike pretty soon people are really drunk and [they start] pulling 
their cameras out and taking pictures[.] $\mathrm{A}$ And in all the pictures you can see the beer in people's hand[.] there's [are] a lot of pictures up [on Facebook] from that.

\section{Authors' Note}

The authors alone are responsible for the content and writing of the article.

\section{Declaration of Conflicting Interests}

The author(s) declared no potential conflicts of interest with respect to the research, authorship, and/or publication of this article.

\section{Funding}

The author(s) disclosed receipt of the following financial support for the research, authorship, and/or publication of this article: This work was supported by the National Institutes of Health (grant number R15DA 027144).

\section{ORCID iD}

Gilbert Quintero $\bigcirc$ https://orcid.org/0000-0001-9507-7841

\section{Notes}

1. A "keg stand" involves an individual being inverted by others over a keg of beer, placing the keg dispensing hose in their mouth, and consuming beer. A "beer bong" is constructed out of a combination of a funnel attached to a tube. The purpose of a beer bong is to facilitate the rapid consumption of alcohol, usually at parties.

2. A beer pyramid is a pyramid-shaped construction of beer cans. These displays can be thought of as something of a monument to beer consumption at parties.

\section{References}

Arnett, J. J. (2005). The developmental context of substance use in emerging adulthood. Joumal of Drug Issues, $32,235-254$.

Backett, K. C., \& Davison, C. (1995). Lifecourse and lifestyle: The social and cultural location of health behaviors. Social Science and Medicine, 40, 629-638.

Becker, H. S. (1996). The epistemology of qualitative research. In R. Jessor, A. Colby, \& R.A. Shweder (Eds.), Ethnography and human development (pp. 53-71). Chicago, IL: University of Chicago Press.

Boyd, D. (2007). Why youth (heart) social network sites: The role of networked publics in teenage social life. In D. Buckingham (Ed.), MacArthur Foundation series on digital learning-Youth, identity, and digital media volume (pp. 119-142). Cambridge, England: MIT Press.

Boyd, D. (2010). Social network sites as networked publics: Affordances, dynamics, and implications. In Z. Pappachirisi (Ed.), A networked self: Identity, community, and culture on social network sites (pp. 39-58). New York, NY: Routledge.

Boyd, D., \& Ellison, N. B. (2008). Social network sites: Definition, history, and scholarship. Journal of ComputerMediated Communication, 13, 210-230.

Brown, R. (2013). A picture tells a thousand stories: Young women, mobile technology, and drinking narratives. In W. Mistral (Ed.), Emerging perspectives on substance misuse (pp. 55-79). Chichester, England: John Wiley, doi: $10.1002 / 9781118306604 . c h 4$

Brown, R., \& Gregg, M. (2012). The pedagogy of regret: Facebook, binge drinking and young women. Continuum, 26, 357-369. doi:10.1080/10304312.2012.665834

Bucholtz, M. (2000). The politics of transcription. Journal of Pragmatics, 32, 1439-1465.

Campbell, S. W. (2007). A cross-cultural comparison of perceptions and uses of mobile telephony. New Media and Society, 9, 343-363. 
Cocker, H. L., Banister, E. N., \& Piacentini, M. G. (2012). The dirty pint: Consumption objects in young people's extreme alcohol consumption and enactment of self. Research in Consumer Behavior, 14, 333-351.

Davis, J. L., \& Chouinard, J. B. (2016). Theorizing affordances: From request to refuse. Bulletin of Science, Technology \& Society, 36, 241-248.

Demant, J. (2009). When alcohol acts: An actor-network approach to teenagers, alcohol and parties. Body \& Saciety, 15, 25-46.

Demant, J., \& Østergaard, J. (2007). Partying as everyday life: Investigations of teenagers' leisure life. Joumal of Youth Studies, 10, 517-537.

Dir, A. L., Cyders, M. A., \& Coskunpinar, A. (2013). From the bar to the bed via mobile phone: A first test of the role of problematic alcohol use, sexting, and impulsivity-related traits in sexual hookups. Computers in Human Behavior, 29, 1664-1670.

eMarketer. (2015). College students still spend most social time with Facebook. Retrieved October 13, 2018, from https://www.emarketer.com/Article/College-Students-Still-Spend-Most-Social-Time-with-Facebook/ 1012955

Fraser, S., Treloar, C., Gendera, S., \& Rance, J. (2017). 'Affording' new approaches to couples who inject drugs: A novel fitpack design for hepatitis C prevention. International Journal of Drug Policy, 50, 19-35.

Gibson, J. J. (1979). The ecological approach to perception. London, England: Houghton Mifflin.

Glassman, T. (2012). Implications for college students posting pictures of themselves drinking alcohol on Facebook. Journal of Alcohol and Drug Education, 56, 38-58.

Gross, R., \& Acquisti, A. (2005). Information revelation and privacy in online social networks. In V. Atluri, S. De Capitani di Vimercati, \& R. Dingledine (Eds.), Proceedings of the ACM workshop on privacy in the electronic society (pp. 71-80). New York, NY: Association for Computing Machinery.

Hart, M. (2017). Being naked on the internet: Young people's selfies as intimate edgework. Joumal of Youth Studies, 20, 301-315.

Hine, C. (2015). Ethnography for the internet: Embedded, embodied and everyday. London, England: Bloomsbury.

Hutchby, I. (2001). Technologies, texts and affordances. Sociology, 35, 441-456.

Johnson, J. C. (1990). Selecting ethnographic informants. Newbury Park, CA: Sage.

Kett, J. F. (1977). Rites of passage: Adolescence in America 1790 to the present. New York, NY: Basic Books.

Latour, B. (2005). Reassembling the social: An introduction to actor-network-theory. Oxford, England: Oxford University Press.

Law, J. (1999). After ANT: Complexity, naming and topology. In J. Law \& J. Hassard (Eds.), Actor network theory and after (pp. 1-14). Oxford, England: Blackwell.

Lipscomb, T. J., Totten, J. W., Cook, R. A., \& Lesch, W. (2007). Cellular phone etiquette among college students. International Joumal of Consumer Studies, 31, 46-56.

Livingstone, S. (2008). Taking risky opportunities in youthful content creation: Teenagers' use of social networking sites for intimacy, privacy and self-expression. New Media \& Saciety, 10, 393-411.

Lyng, S. (2004). Edgework: The sociology of risk-taking. Routledge.

Martinic, M., \& Measham, F. (2008). Swimming with crocodiles: The culture of extreme drinking. Routledge.

Mendelson, A. L., \& Papacharissi, Z. (2010). Look at us: Collective narcissism in college student Facebook photo galleries. In Z. Papacharissi (Ed.), The networked self: Identity, community and culture on social network sites (pp. 251-273). Abingdon, England: Routledge.

Miles, M. B., \& Huberman, A. M. (1994). Qualitative data analysis: An expanded sourcebook. Thousand Oaks, CA: Sage.

Moreno, M. A., \& Egan, K. G. (2011). Alcohol references on undergraduate males' Facebook profiles, American Journal of Men's Health, 5, 413-420.

Moreno, M. A., Parks, M., \& Richardson, L. P. (2007). What are adolescents showing the world about their health risk behaviors on MySpace? Medscape General Medicine, 9, 9. 
Paradise, A. (2012). Picture perfect? College students' experiences and attitudes regarding their photo-related behaviors on Facebook. In L. A. Wankel \& C. Wankel (Eds.), Misbehavior online in higher education (pp. 261-292). Bingley, England: Emerald Group.

Peluchette, J., \& Karl, K. (2010). Examining students' intended image on Facebook: "What were they thinking?!" Journal of Education for Business, 85, 30-37.

Race, K. (2014). Complex events: Drug effects and emergent causality. Contemporary Drug Problems, 41 , 301-334.

Read, B. (2006). Think before you share. The Chronicle of Higher Education. Retrieved August 8, 2013, from http://chronicle.com/article/Think-Before-You-Share/17623

Renfrow, D. G., \& Rollo, E. A. (2014). Sexting on campus: Minimizing perceived risks and neutralizing behaviors. Deviant Behavior, 35, 903-920.

Ryan, G. W., \& Bernard, H. R. (2003). Techniques to identify themes. Field Methods, 15, 85. doi:10.1177/ $1525822 \times 02239569$

Schrock, A. R. (2015). Communicative affordances of mobile media: Portability, availability, locatability, and multimediality. International Journal of Communication, 9, 1229-1246.

Schulenberg, J., Maggs, J. L., Long, S. W., Sher, K. J., Gotham, H. J., Baer, J. S., ... Zucker, R. A. (2001). The problem of college drinking: Insights from a developmental perspective. Alcoholism: Clinical and Experimental Research, 25, 473-477.

Smith, A., Rainie, L., \& Zickhur, K. (2011). College students and technology. Pew Research Center. Retrieved June 8, 2018, from http://www.pewinternet.org/2011/07/19/college-students-and-technology/

Strauss, A., \& Corbin, J. (1998). Basic of qualitative research: Techniques and procedures for developing grounded theory. Thousand Oaks, CA: Sage.

Stutzman, F. (2006). An evaluation of identity-sharing behavior in social network communities. International Digital and Media Arts Joumal, 3, 10-18.

Trotter, R., Needle, R. H., Goosby, E., Bates, C., \& Singer, M. (2001). A methodological model for rapid assessment, response, and evaluation: The RARE program in public health. Field Methods, 13, 137-159.

Winzenburg, S. (2012). In the Facebook Era, students tell you everything. The Chronicle of Higher Education. Retrieved August 8, 2013, from http://chronicle.com/article/In-the-Facebook-Era-Students/133169/

Yoon, K. (2006). Local sociality in young people's mobile communications: A Korean case study. Childhood,13, 155-174.

\section{Author Biographies}

Gilbert Quintero is a professor in the Department of Anthropology at the University of Montana. His research focuses on sociocultural aspects of drug use in several different populations in the United States, including American Indians, Hispanics, and young adult college students. His current interests include the integration of information and communication technologies into social interactions and drug use practices among young adults in collegiate environments and the nonmedical use of pharmaceuticals.

Henry Bundy is a medical anthropology PhD candidate at the University of Kentucky. His dissertation research examines the lives of uninsured safety net care recipients in the South Carolina Upstate.

Michelle Grocke received her $\mathrm{PhD}$ in medical anthropology from the University of Montana in 2016. She is currently an assistant professor and extension specialist in the Department of Health and Human Development at Montana State University. 